\begin{tabular}{|c|c|c|c|}
\hline \multirow{3}{*}{$\begin{array}{r}\text { Case Reports in } \\
\text { Gastroenterology }\end{array}$} & \multirow{2}{*}{\multicolumn{2}{|c|}{ Case Rep Gastroenterol 2018;12:317-321 }} & \multirow[b]{3}{*}{$\begin{array}{l}\text { Karger } \\
\text { Open'access }\end{array}$} \\
\hline & & & \\
\hline & $\begin{array}{l}\text { DOI: } 10.1159 / 000489297 \\
\text { Published online: June 22, } 2018\end{array}$ & $\begin{array}{l}\text { (c) } 2018 \text { The Author(s) } \\
\text { Published by S. Karger AG, Basel } \\
\text { www.karger.com/crg }\end{array}$ & \\
\hline & $\begin{array}{l}\text { This article is licensed under } \\
\text { International License (CC BY-N } \\
\text { Usage and distribution for comm }\end{array}$ & $\begin{array}{l}\text { mons Attribution-NonCommercial } 4.0 \\
\text { rger.com/Services/OpenAccessLicense). } \\
\text { quires written permission. }\end{array}$ & \\
\hline
\end{tabular}

\title{
Gastroparesis in a Patient with Gastric AL Amyloidosis
}

\author{
Matthew Hoscheit ${ }^{a} \quad$ Afrin Kamal $^{\mathrm{b}} \quad$ Michael Cline $^{\mathrm{b}}$ \\ aDepartment of Internal Medicine, Medicine Institute, Cleveland Clinic, \\ Cleveland, $\mathrm{OH}, \mathrm{USA}^{\circ}$ ' Department of Gastroenterology, Digestive Disease Institute, \\ Cleveland Clinic, Cleveland, OH, USA
}

\section{Keywords}

AL amyloidosis · Gastroparesis · Gastrointestinal amyloidosis

\begin{abstract}
Systemic amyloidosis is a group of complex disorders characterized by the extracellular deposition of nonbranching fibrils in various tissues, ultimately leading to a variety of clinical presentations including isolated or multiorgan dysfunction. Amyloid involvement of the gastrointestinal tract is common depending on the subtype of this disease; light chain primary amyloidosis (AL) and secondary amyloidosis (AA) affect the gastrointestinal tract in unique ways due to differing pathophysiology. A case is reported of gastroparesis associated with $A L$ amyloidosis diagnosed by esophagogastroduodenoscopy and study of gastric emptying, then subsequently confirmed by Congo red staining performed on endoscopic biopsies.
\end{abstract}

(C) 2018 The Author(s)

Published by S. Karger AG, Basel

\section{Introduction}

Systemic amyloidosis is a group of complex disorders characterized by the extracellular deposition of nonbranching fibrils in various tissues, ultimately leading to a variety of clinical presentations including isolated or multiorgan dysfunction. Amyloid involvement of the gastrointestinal tract is common depending on the subtype of this disease; light chain primary amyloidosis (AL) and secondary amyloidosis (AA) affect the gastrointestinal tract in unique 


\section{Case Reports in Gastroenterology}

Case Rep Gastroenterol 2018;12:317-321

DOI: 10.1159/000489297

(c) 2018 The A

www.karger.com/crg

Hoscheit et al.: Gastroparesis in a Patient with Gastric AL Amyloidosis

ways due to differing pathophysiology. While these diseases often have subclinical involvement, weight loss, gastrointestinal bleeding, and heartburn are the most common symptoms. Gastroparesis, however, is uncommon and may only been see in $5 \%$ of affected individuals. Without awareness and a heightened suspicion in recognizing this disorder, patients may experience debilitating symptoms of nausea, loss of appetite, and eventual weight loss.

A case is reported of gastroparesis associated with AL amyloidosis diagnosed by esophagogastroduodenoscopy and study of gastric emptying, then subsequently confirmed by Congo red staining performed on endoscopic biopsies.

\section{Case Report}

A 69-year-old female patient with well-controlled type 2 diabetes mellitus ( $\left.\mathrm{HgA}_{1 \mathrm{c}} 6.7 \%\right)$ and two cardiac arrests from pulseless electrical activity preceded by transient third-degree heart block presented to our institution for respiratory failure and an opinion regarding management of long-standing solid food dysphagia, early satiety, and a 15-pound weight loss from a starting weight of 160 pounds ( $9 \%$ total body weight loss) over the past year. Prior workup had included an endoscopy at the outside hospital, demonstrating an esophageal stricture that was endoscopically dilated; no biopsies had been performed. Her hospitalization was unfortunately complicated by a third episode of cardiac arrest with pulseless electrical activity. She suffered aspiration pneumonia and subsequent respiratory failure, prompting her transfer to the Cleveland Clinic.

A physical examination was significant for a chronically ill-appearing, thin female patient with a tracheostomy and PEG tube in place. The rest of the systemic examination was normal. At our institution, serology revealed a hemoglobin level of $8.8 \mathrm{~g} / \mathrm{dL}$ (normal range, 11.5-15.5) and elevated liver function test results, including AST $=67 \mathrm{U} / \mathrm{L}$ (normal range, 13-35), ALT = $72 \mathrm{U} / \mathrm{L}$ (normal range, 7-38), and alkaline phosphatase = 144 U/L (normal range, 32-117). Interestingly, serum free kappa and lambda protein levels were elevated, with a normal kappa/lambda ratio and an $\mathrm{M}$ protein spike on electrophoresis.

A transthoracic echocardiogram demonstrated a small left ventricle with severe upper septal ventricular hypertrophy, a right ventricular systolic pressure of $37 \mathrm{~mm} \mathrm{Hg}$, and an ejection fraction of $67 \%$. A technetium-99m-pyrophosphate infarct scan showed no isotope uptake, suggesting an infiltrating cardiac process. Our patient underwent upper gastrointestinal endoscopy for her dysphagia and weight loss symptoms, revealing a normal mucosal appearance with absent peristalsis and retained gastric contents concerning for gastroparesis. Biopsies were performed; Helicobacter pylori immunostaining was negative, but the pathology was positive for birefringent congophilic deposits in the deep mucosal vessels (Fig. 1). Due to the large amount of gastric content seen on upper gastrointestinal endoscopy despite fasting overnight, our patient underwent a 4-h solid-phase gastric emptying scintigraphy. The results demonstrated $91 \%$ retention of gastric contents at $4 \mathrm{~h}$, consistent with a diagnosis of severe gastroparesis.

With mounting evidence of a systemic disorder involving both cardiac and gastric function, our patient underwent a bone marrow biopsy, revealing $10 \%$ lambda restricted plasma cells and positive staining for Congo red. In view of these clinical findings and investigations, the patient was diagnosed with systemic AL amyloidosis and as a case of biopsy-confirmed gastric amyloid-induced gastroparesis. 


\section{Discussion}

Amyloidoses are a group of diseases that involve the extracellular deposition of insoluble fibrils composed of $\beta$-pleated sheets in various tissues and organs [1]. Various subtypes of this disease exist, including AL amyloidosis from plasma cell dyscrasias, AA amyloidosis from ongoing or recurring inflammation producing serum amyloid A, dialysis-related amyloidosis, and senile and familial amyloidotic polyneuropathy. AL amyloidosis is the most common form of systemic amyloidosis. Its clinical presentation varies and includes nephrotic syndrome with or without renal dysfunction, hepatic dysfunction, heart failure, and autonomic dysfunction. The disease is often difficult to recognize, as virtually any organ other than the brain can be affected, though the heart and kidneys are the organs most often involved [2]. The diagnosis of amyloidosis is often delayed due to the vague nature of its clinical presentation and should be considered in patients presenting with multisystem organ failure. The association between amyloidosis and rheumatoid arthritis as well as multiple myeloma can also guide clinical decision-making. A tissue biopsy is required for the diagnosis of AL amyloidosis.

Amyloidosis may affect the gastrointestinal system in isolation or present with multisystem involvement. Deposition may occur throughout the gastrointestinal tract and liver, leading to clinical manifestations such as intestinal dysmotility, bleeding, pain, malabsorption, or hepatic injury [3]. Ninety-eight percent of patients with diagnosed amyloidosis will have subclinical gastrointestinal involvement [4]. Symptomatic involvement occurs in almost half of patients with gastrointestinal amyloidosis, while $50-95 \%$ of those affected demonstrate effects of hepatic infiltration [5, 6]. Weight loss is the most common symptom (45\%), followed by gastrointestinal bleeding (36\%) and heartburn (33\%) [7]. The incidence of gastroparesis in amyloidosis has not been formally reported, though a prior study suggested that $5 \%$ of affected patients may experience such symptoms [8].

Gastrointestinal amyloidosis varies depending on the subtype of the disease [9]. AA amyloidosis affects the gastrointestinal tract in $60 \%$ of patients, while $1-8 \%$ of patients with AL amyloidosis have gastrointestinal involvement $[10,11]$. Gastrointestinal AL and AA amyloidosis present with differing clinical syndromes due to unique patterns of involvement. Mucosal infiltration of AA amyloid protein may lead to diarrhea and malabsorption syndromes, while muscularis mucosal deposition of AL amyloid often presents with constipation or pseudoobstruction. Additionally, of those patients with AL amyloidosis, $100 \%$ will have duodenal involvement, while $70 \%$ will experience esophageal involvement [12]. Both AL and AA amyloidosis have neuromuscular infiltration leading to impaired or disorganized intestinal contractility. Our patient's presentation of gastroparesis in the setting of AL amyloidosis is consistent with this pattern of AL amyloid deposition and pathology.

A clinical presentation suggestive of amyloidosis should be evaluated by serum and urine electrophoresis and immunofixation. A definitive diagnosis depends on a biopsy of the affected tissue; apple-green birefringence and red staining with Congo red are pathognomonic findings [3]. The amyloid subtype and extent of involvement will direct the therapeutic regimen. Supportive measures remain the mainstay of therapy for the gastrointestinal symptoms of this disease. Given our patient's history of weight loss and cardiac arrest, the decision was made to proceed with inpatient chemotherapy consisting of bortezomib and dexamethasone.

In conclusion, gastrointestinal and hepatic infiltration is common in systemic amyloidosis, and should be suspected in affected patients presenting with malabsorptive or obstructive symptoms. 
Hoscheit et al.: Gastroparesis in a Patient with Gastric AL Amyloidosis

\section{Statement of Ethics}

The authors have no ethical conflicts to disclose.

\section{Disclosure Statement}

All authors declare no financial conflicts of interest.

\section{Author Contributions}

Matthew Hoscheit: manuscript writing; Afrin Kamal: manuscript; Michael Cline: manuscript.

\section{References}

1 Khan MF, Falk RH. Amyloidosis. Postgrad Med J. 2001 Nov;77(913):686-93.

2 Sanchorawala V. Light-chain (AL) amyloidosis: diagnosis and treatment. Clin J Am Soc Nephrol. 2006 Nov;1(6):1331-41.

3 Petre S, Shah IA, Gilani N. Review article: gastrointestinal amyloidosis - clinical features, diagnosis and therapy. Aliment Pharmacol Ther. 2008 Jun;27(11):1006-16.

4 Gilat T, Revach M, Sohar E. Deposition of amyloid in the gastrointestinal tract. Gut. 1969 Feb;10(2):98-104.

5 Buxbaum JN. The amyloid diseases. In: Wyngaarden JB, Smith LH Jr, Bennett JC, editors. Cecil textbook of medicine. 19th ed. Philadelphia: WB Saunders; 1992. p. 1144.

6 Gertz MA, Lacy MQ Dispenzieri A. Amyloidosis. Hematol Oncol Clin North Am 1999 Dec;13(6):1211-33, ix.

7 Cowan AJ, Skinner M, Seldin DC, Berk JL, Lichtenstein DR, O'Hara CJ et al. Amyloidosis of the gastrointestinal tract: a 13-year, single-center, referral experience. Haematologica. 2013 Jan;98(1):141-6.

8 Menke DM, Kyle RA, Fleming CR, Wolfe JT 3rd, Kurtin PJ, Oldenburg WA. Symptomatic gastric amyloidosis in patients with primary systemic amyloidosis. Mayo Clin Proc. 1993 Aug;68(8):763-7.

9 Freudenthaler S, Hegenbart U, Schönland S, Behrens HM, Krüger S, Röcken C. Amyloid in biopsies of the gastrointestinal tract-a retrospective observational study on 542 patients. Virchows Arch. 2016 May;468(5):569-77.

10 Okuda Y, Takasugi K, Oyama T, Onuma M, Oyama H. [Amyloidosis in rheumatoid arthritis - clinical study of 124 histologically proven cases]. Ryumachi. 1994 Dec;34(6):939-46.

11 Menke DM, Kyle RA, Fleming CR, Wolfe JT 3rd, Kurtin PJ, Oldenburg WA. Symptomatic gastric amyloidosis in patients with primary systemic amyloidosis. Mayo Clin Proc. 1993 Aug;68(8):763-7.

12 Gilat T, Revach M, Sohar E. Deposition of amyloid in the gastrointestinal tract. Gut. 1969 Feb;10(2):98-104. 


\begin{tabular}{|c|c|c|}
\hline \multirow{2}{*}{$\begin{array}{l}\text { Case Reports in } \\
\text { Gastroenterology }\end{array}$} & \multicolumn{2}{|c|}{ Case Rep Gastroenterol 2018;12:317-321 } \\
\hline & DOI: $10.1159 / 000489297$ & $\begin{array}{l}\text { () } 2018 \text { The Author(s). Published by S. Karger AG, Basel } \\
\text { www.karger.com/crg }\end{array}$ \\
\hline
\end{tabular}

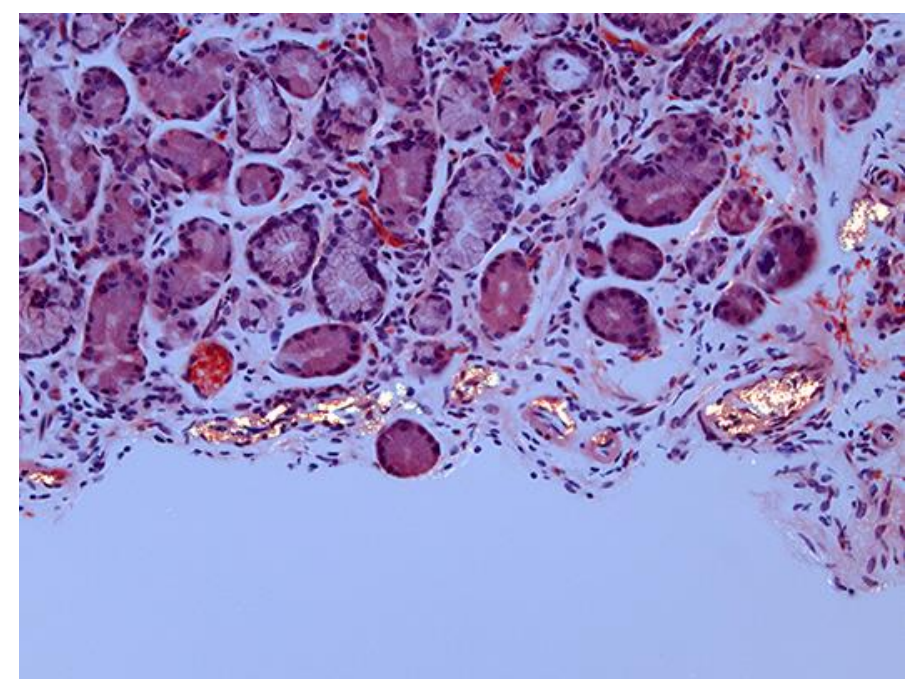

Fig. 1. Gastric antral biopsy with Congo red staining demonstrating birefringent congophilic deposits on the deep mucosal vessels. $\times 200$. Biopsy courtesy of Dr. Ilyssa Gordon, MD, PhD. 